\title{
РОЛЬ АВСТРИИ В ФОРМИРОВАНИИ ДИАЛОГА МЕЖДУ ЕВРОПЕЙСКИМ СОЮЗОМ И ЕВРАЗИЙСКИМ ЭКОНОМИЧЕСКИМ СОЮЗОМ В 2018 Г.
}

\begin{abstract}
Аннотация. В статье анализируется роль Австрийской Республики в формировании диалога между Европейском союзом (ЕС) и Евразийском экономическом союзе (ЕАЭС) в 2018 г. Россия была председателем в ЕАЭС в 2018 г., а Австрия - председателем в Евросоюзе во второй половине этого года. Автор рассматривает основные мероприятия, прошедшие $c$ участием австрийских партнёров, делает вывод о конструктивном вкладе австрийских политиков и предпринимателей в «интеграчию интеграций» и оценивает перспективы сотрудничества с Австрией в этой сфере.
\end{abstract}

Ключевые слова: Евразийский экономический союз, Европейский союз, Евразийская экономическая комиссия, Россия, Австрия, интеграџия интеграџий.

Один из майских указов В.В. Путина (2018 г.) посвящён развитию международной кооперации и содействию отечественного экспорта. В рамках этой задачи предусмотрено завершение формирования общих рынков товаров, услуг, капитала и рабочей силы в рамках Евразийского экономического союза, включая окончательное устранение барьеров, ограничений и отмену изъятий в экономическом сотрудничестве, при одновре́менном активном использовании механизмов совместной проектной деятельности. Российское государство заинтересовано в том, чтобы прогресс евразийского взаимодействия на наднациональном уровне с максимальной эффективностью содействовал использованию внешнего и внутреннего интеграционного потенциала для реализации отечественных стратегических интересов. Кооперация ЕАЭС и ЕС в этом контексте могла бы стать важным фактором, содействующим решению поставленных задач.

Без тесного взаимодействия со структурами Евросоюза основные проекты ЕАЭС (особенно инфраструктурные) в рамках евразийского континента не могут быть полноценно воплощены в жизнь. Несмотря на очевидную востребованность, Брюссель отказывается от переговов с Евразийской экономической комиссией (ЕЭК), руководство которой, тем не менее, продолжает предпринимать попытки начать официальный диалог с Евросоюзом ${ }^{1}$, который объективно остаётся основным западным партнёром ЕАЭС и его членов. У руководства ЕЭК были и остаются хорошие шансы стать эффективным посредником в выстраивании механиз-

(с) Белов Владислав Борисович - кандидат экономических наук. заместитель директора по научной работе. заведуюший Отделом страновых исследований. руководитель Центра германских исследований ИЕ РАН. Aдpec: 125009, Россия, Москва, ул. Моховая, д. 11, стр. 3. E-mail: vladisbelov@yandex.ru.

DOI: http://dx.doi.org/10.15211/vestnikieran32019410

${ }^{1}$ Кондратьева Н.Б. ЕАЭС 2018 глазами экспертов. Аналитическая записка ИЕ РАН, №43(139), 2018 г. (дата обращения: 30.04.2019). 
ма взаимодействия между двумя крупнейшими интеграционными группировками в Европе и на евразийском континенте. Круг вопросов, которые потенциально могут стать предметом для обсуждения, весьма разнообразен - эксперты готовы включить в него десятки позиций ${ }^{1}$.

Во время председательства России в ЕАЭС в 2018 г. ЕЭК предприняла значительные усилия на уровне экспертного сообщества для продвижения идеи о необходимости и пользе начала неформального взаимодействия между двумя интеграционными группировками. С участием её представителей и экспертов прошли десятки конференций, круглых столов и подиумных дискуссий, в т.ч. в Австрии. Эта страна наряду с Италией и Германией, стала одной из основных дискуссионных площадок, посвящённых «интеграции интеграций».

Австрийское государство с его традициями нейтралитета исторически играет одну из ведущих ролей в Европе в области международного посредничества, особенно в сфере политических и экономических отношений между Западом и Востоком европейского континента. Она сохранила эту роль и после вступления в Евросоюз. Резкое ухудшение отношений между Брюсселем и Москвой, введение взаимных санкционных режимов оказало негативное влияние на австрийскую экономику. Не случайно, её политический и экономический истэблишмент постоянно стремится к поиску компромиссных решений в этой области, в т.ч. в контексте обсуждения возможных механизмов взаимодействия между ЕАЭС и ЕС. В первую очередь, это касается конструктивной позиции крупнейших бизнес-ассоциаций Австрии, ориентированных на формирование сотрудничества двух Союзов. Именно они систематически предоставляют площадки для разъяснения позиции ЕЭК.

Австрийские официальные круги в ходе председательства Австрии в ОБСЕ в 2017 г. неоднократно обращали внимание европейских партнеров на потенциал евразийского интеграционного проекта в вопросе укрепления экономической связанности в рамках второй экономической корзины ОБСЕ ${ }^{2}$.

Среди событий с участием австрийских партнёров в 2018 г., посвящённых выстраиванию диалога между ЕС и ЕАЭС, наиболее важными стали мероприятия, проведённые в апреле-мае и октябре-декабре - накануне начала и перед окончанием председательства Австрии в Европейском союзе. В ходе их проведения представители ЕЭК озвучили ряд ключевых сигналов австрийским и европейским участникам в отношении необходимости практической реализации идеи «интеграции интеграций».

Рассмотрим эти мероприятия и послания российской стороны высокопоставленным представителям экономики, политики и экспертного сообщества Австрийской Республики и стран Евросоюза.

Одной из значимых стала конференция «Российско-австрийский экономический диалог», которая прошла 26 апреля 2018 г. в Вене. Мероприятие было посвящено установлению диалога между ведущими экономическими интеграционными объединениями континента ЕС и ЕАЭС, формированию взаимовыгодных торгово-экономических связей между ними, а также перспективам взаимодействия деловых кругов России и Австрии. В мероприятии приняла участие член Коллегии (министр) по интеграции и макроэкономике Евразийской экономической комиссии (ЕЭК) Т.Д. Валовая. Она особо подчеркнула важность проведения экспертного анализа диалога двух экономических союзов, приветствуя усилия австрийских научных центров, работающих над этой темой: «Диалог по линии бизнеса и экспертного сообще-

\footnotetext{
${ }^{1}$ Кондратьева Н.Б. Предпосылки диалога ЕС и ЕАЭС. Научно-аналитический вестник ИЕ РАН, №3, 2018 г. С. 81-85.

2 О важности дальнейшего конструктивного сотрудничества ЕЭК с ОБСЕ во время председательства Австрии неоднократно заявлял Председатель Коллегии ЕЭК Тигран Саркисян. указывая на схожесть целей создания двух объединений, а именно: обеспечение достойных условий для развития стран и народов.
}

Научно-аналитический вестник ИЕ РАН, 2019, №3 
ства позволит нам ... реализовать амбициозные цели по выстраиванию общего экономического пространства» ${ }^{1}$. В этом контексте министр высоко оценила проекты Международного института прикладного анализа (IAASA), расположенного в Вене, и Евразийского банка развития, посвящённые перспективам установления диалога между ЕАЭС и ЕС, о которых будет сказано ниже.

Весьма конструктивными были выступления вице-президента Палаты экономики Австрии Маттиаса Кренна, государственного секретаря Союзного государства Григория Рапоты, президента парламентской группы Австрийской партии свободы Йоханна Гуденуса, директора Российско-австрийского делового совета Анатолия Головатого, директора Фонда «Росконгресс» Александр Стуглева и председателя совета директоров АО «Банк Интеза», президента Ассоциации «Познаем Евразию» Антонио Фаллико.

Накануне конференции (23 апреля) Т. Валовая в Москве в штаб-квартире ЕЭК встретилась с Чрезвычайным и Полномочным Послом Австрийской Республики в РФ Йоханнесом Айгнером, который отметил важность регулярных контактов с представителями ЕЭК и развития взаимовыгодных отношений со странами евразийской «пятерки», в т.ч. в рамках мероприятий, проводимых на площадках международных организаций в Вене, в частности ОБСЕ, где особую роль играет тематика экономической связанности.

В свою очередь, министр отметила важность мероприятий, организуемых бизнес-ассоциациями Австрии, направленных на развитие связей с компаниями стран - членов ЕАЭС и открывающих представителям деловых сообществ возможность синхронизировать графики и повестки дня, намечать оптимальные пути реализации задач по углублению торгово-экономического сотрудничества и получать достоверную информацию об условиях выхода на евразийский рынок. Т. Валовая также напомнила, что в 2017 г. в рамках так называемого Венского процесса после длительного перерыва возобновилась дискуссия о необходимости диалога России и Европейского союза, но уже в новом формате «ЕАЭС - ЕС», и выразила надежду, что ежегодно будут проводиться конференции, а в промежутках - тематические круглые столы ${ }^{2}$.

В конце мая 2018 г. в Вене прошло второе важное мероприятие, предваряющее председательство Австрийской Республики в ЕС - международная конференция «Эффективные многосторонние механизмы в глобализированном мире на примере Европы и Азиатского региона». Оно было организовано Федеральным министерством европейских, интеграционных и иностранных дел Австрии и фактически продолжило цикл конференций, посвящённых экономической взаимосвязанности в Евразии и установлению диалога между интеграционными объединениями континента и проведённых в рамках австрийского председательства в ОБСЕ в 2017 г.

ЕЭК представляла заместитель директора Департамента развития интеграции Евразийской экономической комиссии Гоар Барсегян, подчеркнувшая, что идея сбалансированного и экономически связанного пространства от Лиссабона до Владивостока получает новое звучание и наполнение в контексте обсуждения концепции Евразийского континентального партнёрства (Большой Евразии), и особо отметившая вклад официальных кругов Австрии в фор-

\footnotetext{
${ }^{1}$ Министр ЕЭК Татьяна Валовая: «Развитие интеграции на континенте поможет выстроить общее экономическое пространство». 28.04.2018. URL: http://www.eurasiancommission.org/ru/nae/news/Pages/28-04-2018-1.aspx (дата обращения: 30.04.2019).

2 ЕАЭС и Австрия: обсуждены перспективы сотрудничества. 25.04.2018 URL: http://www.eurasiancommission. org/ru/nae/news/Pages/25-04-2018-4.aspx (дата обращения: 30.04.2019).
}

Научно-аналитический вестник ИЕ РАН, 2019, №3 
мирование его контуров и развитие взаимодействия между ЕАЭС и ЕС ${ }^{1}$.

Не исключено, что вопросы «интеграции интеграций» затрагивались во время первого зарубежного визита в Австрию вновь избранного президента РФ В.В. Путина в начале июня 2018 г. и его краткой рабочей беседы с федеральным канцлером С. Курцем 18 августа 2018 г.

С. Курц в своей речи 3 июля 2018 г. в Европейском парламенте, посвящённой началу председательства Австрии в ЕС, особо отметил необходимость укрепления различных каналов диалога с Россией, без которой невозможен долгосрочный мир в Европе 2 .

Международный центр передовых исследований и сравнительного анализа ЕC-Россия/ CHГ (ICEUR) при поддержке МИД Австрии 10 октября 2018 г. организовал в Вене для представителей австрийских официальных, академических и деловых кругов открытую лекцию министра ЕЭК Т.Д. Валовой по евразийской экономической интеграции. Она обратила их внимание на то, что «для понимания истинных целей евразийского интеграционного проекта необходимо знать его историю и мотивацию его участников, которая на всех этапах была исключительно экономической. В начале 1990-х гг. государства пытались сохранить преимущества единого экономического пространства, существовавшего между ними более 70 лет, и интересно, что тогда ЕС активно поддерживал эти интеграционные начинания; в конце 2000-х, выбрав интеграцию, государства решили дать совместный ответ на случившийся в 2008 г. глобальный экономический и финансовый кризис и, как мы видим сегодня, оказались абсолютно правы и дальновидны... ЕАЭС и ЕС - традиционные и важные торгово-экономические партнёры. И, конечно, с учётом передачи пятью государствами ЕАЭС части полномочий в самых разных сферах экономики на наднациональный уровень привычные двусторонние треки диалога наших стран с ЕС должны быть дополнены сотрудничеством непосредственно двух Союзов и их наднациональных органов - ЕЭК и Европейской комиссии. При этом мы готовы к настолько глубокому диалогу, насколько к нему будут готовы европейские партнёры. Исходим из того, что цели сотрудничества должны быть масштабными и даже амбициозными, только так нам удастся преодолеть нынешний кризис в отношениях» ${ }^{3}$. Последовавшая дискуссия показала, что большинство участников положительно восприняли послание министра.

В начале ноября 2018 г. Г. Барсегян в Вене на заседании Экономико-экологического комитета ОБСЕ указала на ключевой фактор экономической связанности - региональную экономическую интеграцию, в т.ч. евразийскую, которая вносит практический вклад в развитие этой взаимосвязи и стабильности в Евразии, а также выступает драйвером сотрудничества между государствами, способствуя выравниванию диспропорций в экономическом развитии, соответственно, положительно влияя на рост уровня жизни населения. По её мнению, хозяйственную связанность на евразийском континенте необходимо рассматривать сквозь призму традиций партнёрства стран ЕАЭС и ЕС. В этом контексте логично установить полноформатное взаимодействие между союзами - интенсивность диалога о необходимости их взаимодействия на различных уровнях (официальном и между представителями деловых кругов) окажет положительное влияние на торгово-экономические связи на евразийском континенте ${ }^{4}$.

\footnotetext{
${ }^{1}$ Диалог между Европой и Евразией обсудили в Вене. 21.05.2018. URL: http://www.eurasiancommission.org/ru/ nae/ news/Pages/21-05-2018-2.aspx (дата обращения: 30.04.2019).

2 Rede von Bundeskanzler Sebastian Kurz im Europäischen Parlament am 3. Juli 2018 im Wortlaut. URL: https://www.eu2018.at/de/latest-news/news/07-04-Grundsatzrede-vor-dem-Europ-ischen-Parlament---Priorit-ten-des-sterreichischen-EU-Ratsvorsitzes-pr-sentiert.html (дата обращения: 30.04.2019).

${ }^{3}$ Министр ЕЭК Татьяна Валовая: «Диалог между ЕАЭС и ЕС следует начать без предварительных условий и оглядки на политический контекст». 11.10.2018 URL: http://www.eurasiancommission.org/ru/nae/news/Pages/1110-2018-1.aspx (дата обращения: 30.04.2019).

4 Страны ЕАЭС и ЕС могут развивать экономическую связанность в Евразии. 09.11.2018. URL: http://www.eurasiancommission.org/ru/nae/news/Pages/09-11-2018-1.aspx (дата обращения: 30.04.2019).
}

Научно-аналитический вестник ИЕ РАН, 2019, №3 
Завершающим мероприятием в период председательства Австрийской Республики в Европейском союзе в 2018 г. стала конференция «Соединяя Европу и Азию», организованная в начале декабря в Вене обновлённым Бреттон-Вудским комитетом и Национальным банком Австрии. Она была посвящена обсуждению возможных перспектив сотрудничества между ЕАЭС и ЕС. Позицию Евразийской экономической комиссии по вопросам развития интеграционных процессов на континенте представила министр ЕЭК Т.Д. Валовая. В своём выступлении она заявила: «В условиях меняющейся мировой экономической архитектуры отсутствие диалога между нашими союзами недопустимо. Нам следует начать контакты без оглядки на политический контекст, и, уверена, экономические дивиденды и усиление позиций наших стран в мировой экономике, особенно на волне протекционистских тенденций, не заставят себя ждать» ${ }^{1}$. Одновре́менно она подчеркнула, что потенциал сотрудничества ЕАЭС и ЕС, их регулирующих органов - наднациональных комиссий - значителен, и для его полного раскрытия необходим системный диалог, обратив внимание участников конференции на планы ЕЭК по углублению экономического взаимодействия внутри Союза с учетом целей и задач, отражённых в Декларации о дальнейшем развитии интеграционных процессов в рамках ЕАЭС, принятой накануне конференции ${ }^{2}$.

Диалог европейского и евразийского бизнеса подкрепляется совместной аналитической работой, в первую очередь, в рамках кооперации научных центров, расположенных в Австрии. Речь идёт об упомянутом выше совместном проекте Международного института прикладного системного анализа и Евразийского банка развития «Вызовы и возможности экономической интеграции в рамках более широкого европейского и евразийского пространства». Среди его участников - Венский институт международных экономических исследований. В июне 2018 г. состоялась презентация трёх докладов, посвящённых стандартам технической продукции; прямым иностранным инвестициям между ЕС и ЕАЭС и трансевразийским сухопутным транспортным коридорам. Со второй половины 2018 г. началась вторая фаза реализации проекта, которая продлится до 2022 г.

Дискуссии с участием партнёров из Австрии продолжились и в 2019 г. Новой площадкой стал недавно созданный форум австрийской и российской общественности «Сочинский диалог» ${ }^{3}$, сопредседателем которого является Кристоф Ляйтль - бывший руководитель Австрийской экономической палаты, ныне - президент Европейской экономической палаты ${ }^{4}$. Он принадлежит к числу сторонников выстраивания диалога между ЕС и ЕАЭС.

«Сочинский диалог», наряду с другими мероприятиями, проводимыми с австрийскими партнёрами, способен наполнить конкретным содержанием положения Основных направлений международной деятельности Евразийского экономического союза на 2019 г., утверждённых в декабре 2018 г., и во многом учитывающие итоги различных дискуссий, состоявшихся в последние годы в Австрии.

Важны следующие тезисы последнего документа, имеющие прямое отношение к Австрийской Республике: «Комиссия продолжит работу по повышению эффективности взаимодействия ... с европейскими государствами, Европейским союзом, другими региональными объединениями в Европе и иными функционирующими в европейском регионе организаци-

\footnotetext{
${ }^{1}$ ЕАЭС - ЕС: перспективы диалога обсуждены в Вене. 18.12.2018. URL: http://www.eurasiancommission.org/ $\mathrm{ru} / \mathrm{nae} / \mathrm{news} / \mathrm{Pages} / 18-12-2018-3 . a s p x$ (дата обращения: 3004.2019).

2 Итоги ВЕЭС: одобрены программы формирования общих рынков газа, нефти и нефтепродуктов, подписана Декларация о дальнейшем развитии интеграционных процессов в рамках EAЭC. 7.12.2018. URL: http://www.eurasiancommission.org/ru/nae/news/Pages/07_12_2018_1.aspx (дата обращения: 30 апреля 2019).

${ }^{3}$ Первое заседание прошло в мае 2019 г.

${ }^{4}$ Der Traum vom eurasischen Markt führt auch nach Wien. 23.11.2018 https://derstandard.at/2000092129012/DerTraum-vom-eurasischen-Markt-fuehrt-auch-nach-Wien (дата обращения: 30.04.2019).
} Научно-аналитический вестник ИЕ РАН, 2019, №3 
ями. Выстраивание международной деятельности на европейском направлении будет осуществляться с учётом интереса к сотрудничеству с Союзом со стороны правительств, бизнес-сообществ, экспертных кругов, а также их инициатив по организации мероприятий, посвящённых взаимодействию Союза и Европейского союза, и будет направлено на содействие развитию взаимной торговли и либерализацию внешнеэкономической деятельности хозяйствующих субъектов государств-членов, создание диалоговых механизмов для урегулирования возникающих вопросов в ходе такой деятельности, а также на установление контактов с представителями официальных кругов и институциализацию сотрудничества с правительствами государств европейского региона... Государства-члены будут оказывать поддержку проводимым в рамках заключённых меморандумов форумам, конференциям, круглым столам и т.п. посредством информационного сопровождения и содействия в формировании делегаций представителей бизнес-сообществ и органов исполнительной власти государств-членов... Продолжится взаимодействие с международным деловым и экспертным сообществом, в том числе с торгово-промышленными палатами, советами делового сотрудничества, региональными банками развития и ключевыми международными дискуссионными площадками, включая Всемирный экономический форум, Международный институт прикладного системного анализа и др.» .

Выразим надежду на то, что в юбилейном для евразийской интеграции 2019 г. (25-летие выдвижения Н. Назарбаевым идеи этого интеграционного проекта и 5-летие подписания договора о ЕАЭС) неформальное сотрудничество ЕЭК с официальными и неофициальными представителями государств Евросоюза, в первую очередь с Австрией, внесёт важный вклад в дальнейшее выстраивание диалога между двумя ведущими европейскими интеграционными образованиями. Представители российской академической науки, особенно НИ ИМЭМО им. Е.M. Примакова РАН и Институт Европы РАН, готовы оказать содействие в этом процессе.

\section{Список литературы}

Белов В.Б. Итоги председательства России в ЕАЭС в 2018 г. Научно-аналитический Вестник ИЕ РАН, №2, 2019. С. 13-19.

Кондратьева Н.Б. Предпосылки диалога ЕС и ЕАЭС. Научно-аналитический Вестник ИЕ РАН, №3, 2018. С. 81-85.

Основные направления международной деятельности Евразийского экономического союза на 2019 год. URL: http://docs.cntd.ru/document/551866205.

Декларация о дальнейшем развитии интеграционных процессов в рамках EAЭC. URL: http://mineconom.gov.kg/froala/uploads/file/45a8f08e924179dd90dc82fe40ecc84c11fbec24.pdf.

\section{References}

Belov V.B. Itogi predsedatel'stva Rossii v YEAES v 2018 g. Nauchno-analiticheskiy Vestnik IYe RAN, №2, 2019. S. 13-19.

Kondrat'yeva N.B. Predposylki dialoga YES i YEAES. Nauchno-analiticheskiy Vestnik IYe RAN, №3, 2018. S. 81-85.

Osnovnyye napravleniya mezhdunarodnoy deyatel'nosti Yevraziyskogo ekonomicheskogo soyuza na 2019 god. URL: http://docs.cntd.ru/document/551866205.

Deklaratsiya o dal'neyshem razvitii integratsionnykh protsessov $\mathrm{v}$ ramkakh YEAES. URL: http://mineconom.gov.kg/froala/uploads/file/45a8f08e924179dd90dc82fe40ecc84c11fbec24.pdf.

\footnotetext{
${ }^{1}$ Основные направления международной деятельности Евразийского экономического союза на 2019 год. URL: http://docs.cntd.ru/document/551866205 (дата обращения: 30.04.2019).
} 


\section{The role of Austria in the shaping the dialogue between the European Union and the Eurasian Economic Union in 2018}

Author. Vladislav Belov, Candidate of Sciences (Economics), Deputy Director of IE RAS, Head of Department for Countries Researches, Head of Center for German Studies, Institute of Europe, Russian Academy of Sciences. Address: 11-3, Mokhovaya str., Moscow, Russia, 125009. Email: vladisbelov@yandex

Abstract. The article analyzes the role of the Republic of Austria in shaping the dialogue between the European Union (EU) and the Eurasian Economic Union (EAEU) in 2018. Russia was the chairman of the EAEU in 2018, and Austria was the chairman of the European Union in the second half of this year. The author examines the main events held with the participation of the Austrian partners, concludes that the Austrian politicians and entrepreneurs have made a constructive contribution to the «integration of integrations» and assesses the prospects for cooperation with Austria in this area.

Keywords. Eurasian Economic Union, European Union, Eurasian Economic Commission, Russia, Austria, integration of integrations.

DOI: http://dx.doi.org/10.15211/vestnikieran32019410 